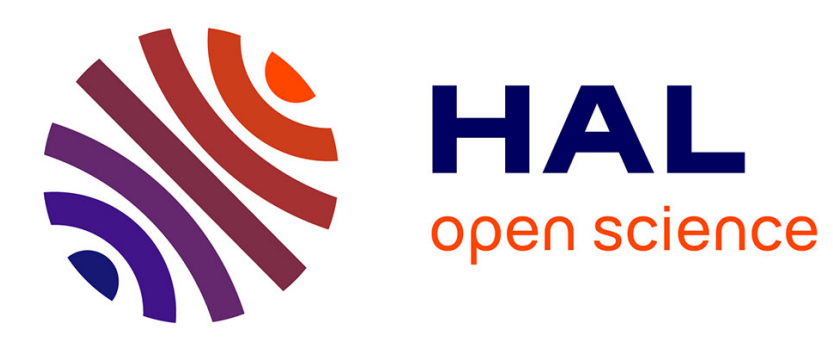

\title{
A vibration sensor, using telecommunication grade monomode fiber, immune to temperature variations
}

F. Pigeon, S. Pelissier, A. Mure-Ravaud, H. Gagnaire, S. I. Hosain, C. Veillas

\section{To cite this version:}

F. Pigeon, S. Pelissier, A. Mure-Ravaud, H. Gagnaire, S. I. Hosain, et al.. A vibration sensor, using telecommunication grade monomode fiber, immune to temperature variations. Journal de Physique III, 1993, 3 (9), pp.1835-1838. 10.1051/jp3:1993243 . jpa-00249046

\section{HAL Id: jpa-00249046 https://hal.science/jpa-00249046}

Submitted on 1 Jan 1993

HAL is a multi-disciplinary open access archive for the deposit and dissemination of scientific research documents, whether they are published or not. The documents may come from teaching and research institutions in France or abroad, or from public or private research centers.
L'archive ouverte pluridisciplinaire HAL, est destinée au dépôt et à la diffusion de documents scientifiques de niveau recherche, publiés ou non, émanant des établissements d'enseignement et de recherche français ou étrangers, des laboratoires publics ou privés. 
Classification

Physics Abstracts

$06.70 \mathrm{D}-07.60 \mathrm{~F}$

\title{
Short Communication
}

\section{A vibration sensor, using telecommunication grade monomode fiber, immune to temperature variations}

\author{
F. Pigeon, S. Pelissier, A. Mure-Ravaud, H. Gagnaire, S. I. Hosain (*) and C. Veillas \\ Laboratoire Traitement du Signal et Instrumentation, U.A. CNRS 842, Faculté des Sciences, 23 \\ rue du Docteur Paul Michelon, 42023 Saint-Etienne Cedex 2, France
}

(Received 14 June 1993, accepted 4 August 1993)

\begin{abstract}
A polarimetric fiber-optic vibration sensor immune to temperature variations is realized by forming coils using a standard single-mode fiber. The phase drift due to the linear birefringence changes induced by a modification of the environmental temperature is balanced by a feedback compression of a non vibrating coil. Experimental results show that without the feedback system the sensitivity to temperature is equal to $2 \% /{ }^{\circ} \mathrm{C}$. The compensated device has a maximum $10 \%$ relative variation of the output signal over a $30-55^{\circ} \mathrm{C}$ range. This method is easy to implement on polarimetric sensors over any range of temperature.
\end{abstract}

\section{Introduction.}

Among the many existing transducers based on optical fibers, we are particularly interested in the polarization modulation devices [1] because these are easy to be implemented [2]. The use of telecommunication grade monomode fiber is very interesting because these are the principal fibers used all over the world. A disadvantage of such a sensor is its temperature dependence which is high because the fiber birefringence changes due to thermal expansion [2].

This paper deals with a polarimetric sensor for mechanical vibrations immune to temperature variations. Recently a temperature insensitive fiber optic displacement sensor based on the bending induced birefrigence has been proposed by Imaï et al. [3]. The fiber transducer in their method consists of a pair of coils of flat PANDA type polarization maintaining fibers spliced with their polarization axes at right angles to each other. This principle cannot be used with a monomode telecommunication grade fiber because of lack of polarization axes.

It is known that the linear birefringence in a monomode telecommunication grade fiber can be changed either due to a change in the bending radius or due to a change of temperatur [3]. In

(*) On leave from Physics Department, Ravenshaw College, Cuttack-753003, India. 
our method we have compensated the change of birefringence due to variation of temperature of a vibrating coil by appropriately introducing a variation of radius of curvature of an auxiliary fiber coil. The time variation of birefringence due to change of temperature is a very low frequency phenomenon (much less than $1 \mathrm{~Hz}$ ). As we are interested to measure the vibration in the $1 \mathrm{~Hz}$ to $1 \mathrm{kHz}$ range, a frequency filter is used to separate the polarization modulation induced by temperature from that induced by vibration. Thus to compensate the perturbation due to temperature variation, we have used a feedback system (Fig. 1).

\section{Working principle.}

The experimental set-up is shown in figure 1. Light from the He-Ne laser is circularly polarized by a quater wave plate and is then focussed onto the end of the fiber using a microscope objective. A few meters of single-mode optical fiber (34 ST 1101 from EOTec Corporation) is used. The polarization state at the end of the fiber is determined with a Wollaston prism and two photodiodes. The sensing element is a coil $\left(B_{\mathbf{s}}\right)$ of this fiber with a single turn of $26 \mathrm{~mm}$ diameter. The mechanical vibrations applied on a point of the coil modify its radius of curvature and hence the birefringence of the fiber.

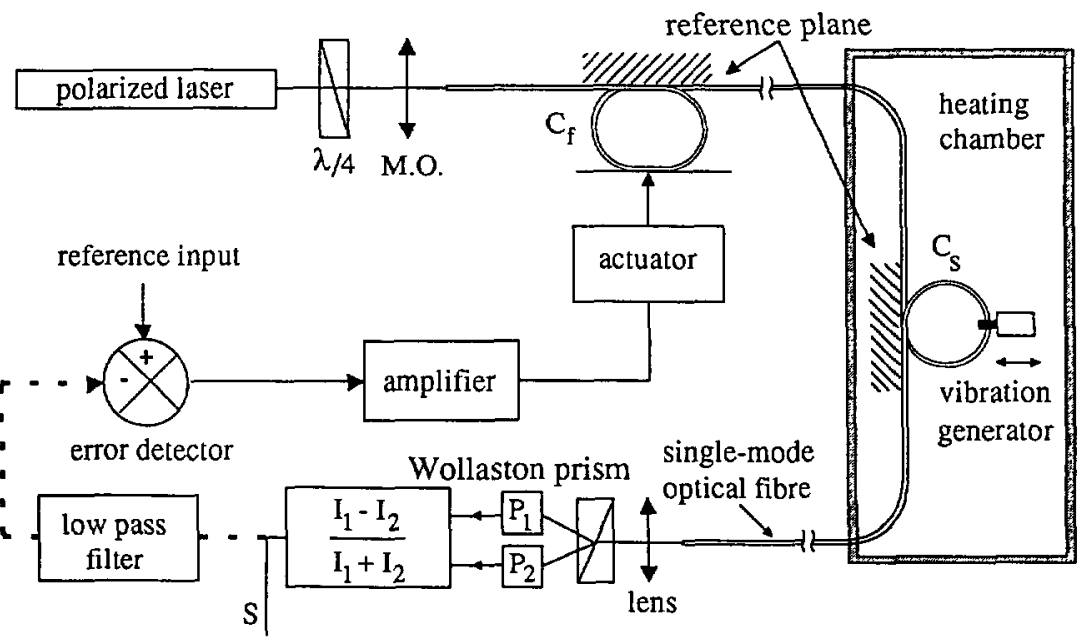

Fig. 1. - Experimental set-up.

The auxiliary coil $B_{\mathrm{f}}$ is achieved in the same fiber by making a solenoidal winding of nine turns each of diameter $26 \mathrm{~mm}$. The radius of curvature can be varied by compressing $B_{\mathrm{f}}$ with the help of an actuator.

Because of the turns in the coils and other unintentional twists, the fiber possesses some circular birefringence which is not negligible in comparison to the linear birefringence. We have studied in the absence of vibration, the variations of parameters of birefringence for various compressions of $B_{\mathrm{f}}$. The two parameters are $\theta_{\mathrm{a}}$ and $\phi_{0} \cdot \theta_{\mathrm{a}}$ is the orientation of the Wollaston prism corresponding to maximum signal intensity (this is a parameter associated with the setup). $\phi_{0}$ is the phase difference between the two orthogonal linearly polarized modes. From the measurement of the detected signal $S$, we compute $\left|\sin \phi_{0}\right|$ as described in reference [4]. The 


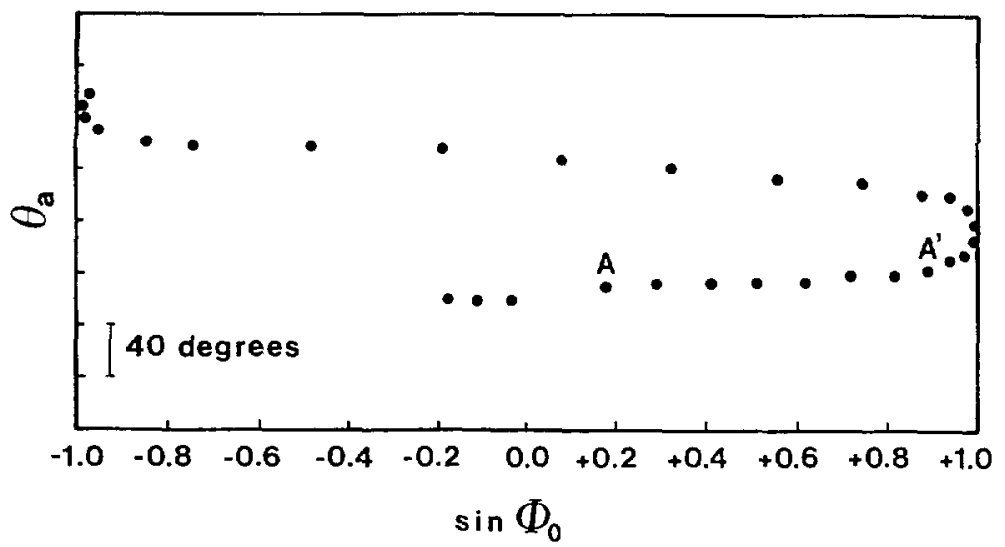

Fig. 2. - Variations of the parameters $\theta_{\mathrm{a}}$ and $\sin \phi_{0}$ for various compressions of the auxiliary coil $B_{\mathrm{f}}$.

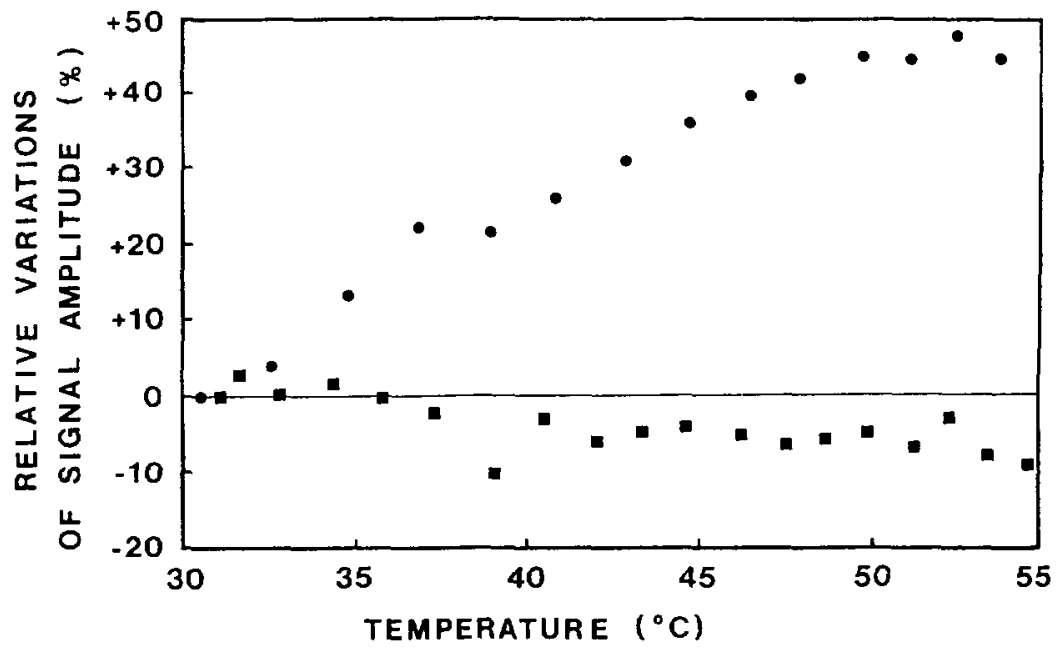

Fig. 3. - Experimental results. (n) with automatized feedback (temperature compensated system). $(\bullet)$ without automatized feedback (without temperature compensation).

experimental results are presented in figure 2 , in which each point corresponds to a compression of $B_{\mathrm{f}}$.

In our experiment, optimum sensing conditions are obtained with the values of the parameters $\theta_{\mathrm{a}}$ and $\phi_{0}$ corresponding to the "bias point" A shown in figure 2 . In this condition a theoretical investigation of the device has shown that $S$ is proportional to the displacement of the moving body in contact with $B_{\mathbf{s}}[4]$. The change in temperature shifts the working point from optimum position. By introducing a suitable compression of the auxiliary coil $B_{\mathrm{f}}$ the working point is again brought back to its optimum position. 


\section{Experiments and results.}

This sensor allows the measurement of vibration amplitudes in the range of $10 \mu \mathrm{m}$ to $1 \mathrm{~cm}$ and frequencies in the range of $0.5 \mathrm{~Hz}$ to $2 \mathrm{kHz}$. To simulate pratical conditions of use of such a sensor, the length of the fiber employed is much greater than that needed for the sensing element. The fiber is put in a heating chamber as shown in figure 1 . When the temperature inside the chamber is varied, the value of $\phi_{0}$ varies and the "bias point" moves. A vibration with a constant amplitude of $1 \mathrm{~mm}$ is applied on $B_{\mathrm{s}}$ and the temperature is varied from 30 to $55^{\circ} \mathrm{C}$. As expected the bias point moves from $A$ to $A^{\prime}$ (Fig. 2) resulting in distortion along with increase of the detected signal amplitude. A typical experimental result showing the relative variations of signal amplitude with temperature is presented in figure 3 . The upper points in the figure correspond to results without compensation for the temperature variations and the lower points correspond to the compensated system.

\section{Conclusion.}

We have developed a polarimetric fiber-optic vibration sensor immune to environmental temperature variations over a large range. Although the measurements were made for a range of $30{ }^{\circ} \mathrm{C}$ our system can operate even for a larger range. The main advantage of the device is that it is easy to implement and needs only basic components such as a monomode telecommunication grade fiber and a simple electronic circuit. Although we have used a special fiber operating at $0.6 \mu \mathrm{m}$ wavelength, our device can operate also with a telecommunication grade fiber (operating at $1.3 \mu \mathrm{m}$ ) with a proper choice of the source of light.

\section{References}

[1] Pigeon F., Pelissier S., Mure-Ravaud A., Gagnaire H. and Veillas C., Optical fiber Young modulus measurement using an optical method, Electron. Lett. 28 (1992) 1034-1035.

[2] Eickhoff W., Temperature sensing by mode-mode interference in birefringent optical fibers, Opt. Lett. 6 (1981) 204.

[3] Imaï Y., Rodrigues M.A. and lizuka K., Temperature insensitive fiber coil sensor for altimeters, Appl. Opt. 29 (1990) 975-978.

[4] Pigeon F., Mure-Ravaud A., Veillas C. and Gagnaire H., Utilisation d'une fibre optique unimodale standard en capteur polarimétrique. Application à la détection de vibration mécanique, $J$. Phys. III France 1 (1991) 1323-1335. 